\title{
Rates and predictors of depression status among caregivers of patients with COPD hospitalized for acute exacerbations: a prospective study
}

This article was published in the following Dove Press journal:

International Journal of COPD

14 December 2016

Number of times this article has been viewed

\author{
Roberto Bernabeu-Mora ${ }^{1-3}$ \\ Gloria García-Guillamón² \\ Joaquina Montilla- \\ Herrador ${ }^{2,3}$ \\ Pilar Escolar-Reina ${ }^{2,3}$ \\ José Antonio García-Vidal ${ }^{2}$ \\ Francesc Medina-Mirapeix ${ }^{2,3}$ \\ 'Division of Pneumology, Hospital \\ Morales Meseguer, ${ }^{2}$ Department \\ of Physical Therapy, University of \\ Murcia, ${ }^{3}$ Physiotherapy and Disability \\ Research Group, Instituto Murciano \\ de Investigación Biosanitaria Virgen de \\ la Arrixaca (IMIB), Murcia, Spain
}

Background: Hospitalization is common for acute exacerbation of COPD, but little is known about its impact on the mental health of caregivers.

Objective: The aim of this study was to determine the rates and predictors of depressive symptoms in caregivers at the time of hospitalization for acute exacerbation of COPD and to identify the probability and predictors of subsequent changes in depressive status 3 months after discharge.

Materials and methods: This was a prospective study. Depression symptoms were measured in 87 caregivers of patients hospitalized for exacerbation at hospitalization and 3 months after discharge. We measured factors from four domains: context of care, caregiving demands, caregiver resources, and patient characteristics. Univariate and multivariate multiple logistic regressions were used to determine the predictors of depression at hospitalization and subsequent changes at 3 months.

Results: A total of 45 caregivers reported depression at the time of hospitalization. After multiple adjustments, spousal relationship, dyspnea, and severe airflow limitation were the strongest independent predictors of depression at hospitalization. Of these 45 caregivers, $40 \%$ had a remission of their depression 3 months after discharge. In contrast, $16.7 \%$ of caregivers who were not depressive at hospitalization became depressive at 3 months. Caregivers caring $>20$ hours per week for patients with dependencies had decreased odds of remission, and patients having dependencies after discharge increased the odds of caregivers becoming depressed.

Conclusion: Depressive symptoms are common among caregivers when patients are hospitalized for exacerbation of COPD. Although illness factors are determinants of depression at hospitalization, patient dependence determines fluctuations in the depressive status of caregivers.

Keywords: caregivers, COPD, depression, acute care, family care

\section{Introduction}

COPD is a common, preventable and treatable disease that is characterized by peristent respiratory symptoms and airflow limitation. Periods of disease stability are punctuated by acute exacerbations, which often require medical intervention and hospitalization. ${ }^{1}$ Treatment is aimed at promoting self-management and providing supportive care. ${ }^{2}$ Most individuals with COPD live in a community in which relatives and friends are the main providers of care for disease management. ${ }^{3}$ Unfortunately, caregiving can often have serious adverse health and personal consequences for caregivers. Depressive symptoms are commonly reported by caregivers of patients with $\mathrm{COPD},{ }^{4-6}$ with a frequency similar to that of depressive symptoms among caregivers of patients with mental illness or cancer. ${ }^{4}$
Correspondence: Roberto

Bernabeu-Mora

Division of Pneumology, Hospital

General Universitario Morales Meseguer,

Avda Marqués de los Velez s/n,

30008 Murcia, Spain

Tel +34968360900

Fax +34968360994

Email rbernabeumora@hotmail.co 
Previous studies have shown that the patient's level of dependence and perceived burden are very strong determinants of depression for caregivers of patients with COPD. ${ }^{4,6}$ Qualitative studies have reported that the occurrence of exacerbations and whether the patient will recover from them are distressing situations for caregivers. ${ }^{7}$ However, the role of exacerbations in the development of new episodes of depression is not well understood. Also, little is known about how depression persists or remits after hospitalization for acute exacerbation of COPD and factors that may predict remission from depression. Although the existing literature provides some insight into the characteristics of caregivers likely to have depression in the community, ${ }^{4,6,8}$ factors associated with the occurrence of depression at the time of hospitalization or with its remission after hospitalization could differ.

The present study addressed these questions in a cohort of caregivers of patients hospitalized for exacerbation of COPD. The objectives were to determine the rates and predictors of depressive symptoms at the time of hospitalization for exacerbation of COPD and to identify the probability and predictors of subsequent changes in the caregiver's depressive status 3 months after discharge.

\section{Materials and methods Study design and participants}

Caregivers of patients hospitalized for exacerbation of their COPD were prospectively recruited at Morales Meseguer Hospital, Murcia, Spain. Participants were included if they were the primary caregiver (ie, the person who, before hospitalization, provided the most physical and/or supportive care without receiving any payment) and 18 years of age or older. Potential participants were excluded if they or their patients had significant cognitive deficits (ie, Mini-Mental State Examination Score of $<20$ ), or if patients were younger than 40 years old, had a terminal illness (survival expected to be $<4$ months), lived outside the hospital's catchment area, or had a length of stay of $>30$ days.

On the basis of patient health examinations and a review of the patients' electronic files, a pulmonary physician identified and recruited a consecutive sample of eligible caregivers during a 1-year period. All study participants provided written informed consent, and the study protocol was approved by The Institutional Review Board of the Morales Meseguer Hospital (EST-35/13).

\section{Measures}

Data were collected in face-to-face interviews separately with caregivers and their patients 48-96 hours after hospital admission and in phone interviews 3 months after hospital discharge. Patients were interviewed for measuring potential predictor variables (eg, dyspnea, frailty, and level of dependence). When patients were unable to be interviewed or contacted at home, the primary caregiver was interviewed as a surrogate because they may also provide accurate information.

We used the depression subscale of the Goldberg test to highlight the presence or absence of depressive symptoms., ${ }^{910}$ This scale includes nine items that ask respondents to rate the presence of symptoms using binary response categories (yes/no). Scores range from 0 to 9 , and a cutoff of 2 is used to discriminate patients with depressive symptoms $(\geq 2)$ from those without symptoms $(<2) .{ }^{9}$ This instrument was administered at the hospital at admission and at home 3 months after discharge.

\section{Potential predictor variables}

Variables were chosen based on their potential association with depression as indicated throughout the literature and conceptual framework. ${ }^{6,11}$ These variables were classified into four domains that may contribute to depression: context of care, caregiving demands, caregiver resources, and patient characteristics.

The context of care included the caregiver's age and gender, cohabitation (yes/no), and kin relationship (spousepartner/other) with the patient. Caregiving demands were related to the caregiving period (months), hours per week, and caregiver's burden. Caregiving period and hours per week were measured at the hospital regarding the patient's pre-exacerbation status and dichotomized as described elsewhere. ${ }^{5,6}$ Burden was measured at the hospital and again 3 months after discharge by the Zarit Caregiver Burden Interview (ZBI), ${ }^{12}$ which has already been used to measure caregiver burden of patients with COPD. ${ }^{13}$ The ZBI included 22 items using a 5-point response scale ranging from "never" to "almost always". Its summative score was categorized into low, moderate, or high burden.

Caregiver resources were help from another caregiver (yes/no) and perceived social support. The latter was measured by the Duke UNC questionnaire, which includes 11 items for measuring two subscales: affective (receiving tokens of affection) and confidential (having someone to discuss concerns) support. These items asked respondents to indicate how they felt using a 5-point response scale ranging from "much less than what I want" to "much as I want". A summative score was obtained per subscale and categorized as scarce or normal support. ${ }^{14,15}$

Patient characteristics included airflow limitation, the modified Medical Research Council Dyspnea Scale, frailty, 
and level of dependence. Airflow limitation was extracted from electronic files on the patient's last control visit for COPD before hospitalization. Frailty was measured at the hospital by means of the Reported Edmonton Frail Scale based on a scale from 0 to 18 , where higher scores indicate more severe frailty. ${ }^{16}$ Dyspnea and dependence were measured at the hospital and again 3 months after discharge. Dependence was measured by a scale of six activities of daily living (ADLs: toileting, bathing, transferring, eating, dressing, and walking across a small room) as described elsewhere. ${ }^{17}$ Dependence was defined as self-reporting being unable to perform an ADL or requiring the help of another person for any ADL. The score range for this scale (0-6) was based on the number of dependencies, with a score of 6 representing dependencies in all ADLs.

\section{Statistical analysis}

We used descriptive statistics, including Pearson $\chi^{2}$ and independent $t$-tests, to summarize variables regarding the four domains between caregivers with and without depressive symptoms. Multivariate logistic regression analyses were used to assess the possible factors associated with depression at baseline. Separate multivariate models were fit for each of the four domains by including all their variables as independent variables. A final multivariate logistic regression model was chosen by including the most strongly predictive factors from each of the individual models, as well as variables significant at the 0.10 level. All multivariate models were produced using the back-step method. Goodness-of-fit and regression diagnostics were assessed as described elsewhere. ${ }^{18}$

Caregivers who had depressive symptoms at baseline and did not have symptoms at the end of study were classified as having remission (yes/no). Caregivers who were depressionfree at the hospital and became depressive were classified as having a new episode of depression (yes/no).

Univariate and multivariate logistic regression analyses were used to assess the possible factors associated with both having remission and a new episode after hospital discharge, which were used as dependent variables. In the univariate analyses, all potential predictors were tested for a significant relationship $(P<0.10)$. Two multivariable analyses were then performed using the relative factors with significant contributions $(P<0.10)$ in the univariate analyses. All univariate models used the enter method, and the multivariate models were produced using the back-step method. Goodness-of-fit and regression diagnostics for the models were assessed as described elsewhere. ${ }^{19}$
The sample size calculation was based on the rule of thumb that 15 subjects are needed per predictor for a reliable equation. ${ }^{19}$ We recruited a minimum of 75 participants assuming a maximum of five predictors. All analyses were performed using the Statistical Package for the Social Sciences (SPSS) statistical software program (SPSS version 19.0; IBM SPSS, Chicago, IL, USA).

\section{Results}

A total of 107 patients were hospitalized for acute exacerbation of COPD during the study period. Of these patients, 90 reported having a usual caregiver at home. All caregivers agreed to participate in the study, but three were excluded because their patients had a length of stay longer than 30 days. Therefore, 87 caregivers were finally included at baseline. Eighty-four of the caregivers participated again 3 months after hospital discharge. Of the three caregivers lost to follow-up, two died and one dropped out of the study because the patient died.

Forty-five caregivers of patients $(51.7 \%)$ in our sample reported depressive symptoms at baseline. Data on the context and demands of care, caregiver resources, and patient characteristics are provided in Table 1 for caregivers with and without depression. A higher percentage of caregivers with depressive symptoms had a moderate-to-high level of perceived burden and scarce levels of social support compared to those without symptoms.

The results of the multivariate models of predictors of caregiver depression at the time of hospitalization for COPD are shown in Table 2. Model 1, which included context of care, suggests that spousal caregiving may be associated with higher odds of caregiver depression. The model of caregiving demands (Model 2) suggested that a moderate and high burden of care is associated with greater odds of caregiver depression. Model 3 examined caregiver resources but did not identify any relevant factor. More relevant Patient characteristics (Model 4) were severity of airflow limitation and dyspnea. In the final model, spousal caregiving, having dyspnea, and severe airflow limitation were the strongest independent predictors of caregiver depression at the time of hospitalization of COPD.

Figure 1 shows the probability of change between the states of depression, nondepression, and death 3 months after hospital discharge. The arrows represent the likelihood that a subject who started depressed or not depressed remains in that state or changes to another state 3 months later. Of the 45 caregivers who reported depression at hospitalization, 18 (40\%) were depression-free 3 months 
Table I Baseline characteristics of caregivers with and without depressive symptoms

\begin{tabular}{|c|c|c|c|}
\hline Variables & $\begin{array}{l}\text { No symptoms } \\
(n=42)\end{array}$ & $\begin{array}{l}\text { Depression } \\
(n=45)\end{array}$ & $P$-value \\
\hline \multicolumn{4}{|l|}{ Context of care } \\
\hline $\begin{array}{l}\text { Ages in years, } \\
\text { mean } \pm S D\end{array}$ & $61.79 \pm 12.82$ & $62.91 \pm 13.49$ & 0.69 \\
\hline \multicolumn{4}{|l|}{ Gender } \\
\hline Female & $35(83.30)$ & $43(95.60)$ & 0.13 \\
\hline Male & $7(16.70)$ & $2(4.40)$ & \\
\hline \multicolumn{4}{|l|}{$\begin{array}{l}\text { Relationship with the } \\
\text { patient }\end{array}$} \\
\hline Spouse/partner & $27(64.30)$ & $37(82.20)$ & 0.06 \\
\hline Other & $15(35.70)$ & $8(17.80)$ & \\
\hline \multicolumn{4}{|l|}{ Cohabitation } \\
\hline Yes & $35(83.30)$ & $39(86.70)$ & 0.66 \\
\hline No & $7(16.70)$ & $6(13.30)$ & \\
\hline \multicolumn{4}{|l|}{ Caregiving demands } \\
\hline \multicolumn{4}{|c|}{ Caregiving period, year } \\
\hline$\leq 1$ & $5(11.90)$ & $2(4.40)$ & 0.38 \\
\hline$>1$ & $37(88.10)$ & $43(95.60)$ & \\
\hline \multicolumn{4}{|c|}{ Caregiving hours per week } \\
\hline$\leq 20$ & $10(23.80)$ & II (24.40) & 0.95 \\
\hline$>20$ & $32(76.20)$ & $34(75.60)$ & \\
\hline \multicolumn{4}{|l|}{ Caregiver's burden } \\
\hline Low & $35(83.30)$ & $26(57.80)$ & 0.03 \\
\hline Moderate & $3(7.10)$ & $8(17.80)$ & \\
\hline High & $4(9.50)$ & II (24.40) & \\
\hline \multicolumn{4}{|l|}{ Caregiver resources } \\
\hline \multicolumn{4}{|l|}{ Affective support } \\
\hline Normal & $37(88.10)$ & $30(66.70)$ & 0.02 \\
\hline Scarce & $5(11.90)$ & $15(33.30)$ & \\
\hline \multicolumn{4}{|l|}{ Confidential support } \\
\hline Normal & $38(90.50)$ & $33(73.30)$ & 0.04 \\
\hline Scarce & $4(9.50)$ & $12(26.70)$ & \\
\hline \multirow{2}{*}{\multicolumn{4}{|c|}{$\begin{array}{l}\text { Receive help from other } \\
\text { caregivers }\end{array}$}} \\
\hline & & & \\
\hline Yes & $10(23.80)$ & $9(20.00)$ & 0.67 \\
\hline No & $32(76.20)$ & $36(80.00)$ & \\
\hline \multicolumn{4}{|c|}{ Patient characteristics } \\
\hline \multicolumn{4}{|c|}{ Airflow limitation } \\
\hline Mild/moderate & $33(78.60)$ & $21(46.70)$ & 0.00 \\
\hline Severe/very severe & $9(21.40)$ & $24(53.30)$ & \\
\hline \multicolumn{4}{|l|}{ Dyspnea score } \\
\hline $0-1$ & II (26.20) & $5(11.60)$ & 0.14 \\
\hline 2 & $8(19.00)$ & $6(14.00)$ & \\
\hline$\geq 3$ & $23(54.80)$ & $32(74.40)$ & \\
\hline \multicolumn{4}{|l|}{ Frailty } \\
\hline Not frail & $12(28.60)$ & $10(22.20)$ & 0.26 \\
\hline Vulnerable & $10(23.80)$ & $6(13.30)$ & \\
\hline Frail & $20(47.60)$ & $29(64.40)$ & \\
\hline \multicolumn{4}{|c|}{ Number of dependencies } \\
\hline $0-2$ & $35(83.30)$ & $37(82.20)$ & 0.89 \\
\hline$\geq 3$ & $7(16.70)$ & $8(17.80)$ & \\
\hline
\end{tabular}

Note: Data are given as $\mathrm{n}(\%)$ unless otherwise noted. Abbreviation: SD, standard deviation.

after hospital discharge, 25 (55.6\%) continued to report depressive symptoms, and 2 (4.4\%) died. In contrast, 34 (80.9\%) of the caregivers who were not depressed at hospitalization remained depression-free at 3 months, 7 (16.7\%) became depressive, and 1 (2.3\%) dropped out. At 3 months, a total of 32 caregivers (38\% of the 84 participants) had depression.

The results of multivariate models for predictors of remission and new episodes of caregiver depression 3 months after hospital discharge are shown in Table 3. In the univariate logistic regression analyses (not shown), only the number of dependencies $(P=0.06)$ and hours per week $(P=0.01)$ were associated with remission (although the first was considered trend and not statistically significant), and only perceived burden $(P=0.03)$ and number of dependencies $(P=0.01)$ were associated with new episodes. According to the first multivariate model, providing care $>20$ hours per week and dependence at home in three or more daily activities decreased the odds of remission. In addition, the patient having this level of dependence at home increased the odds of the caregiver becoming depressed after hospital discharge. Perceived burden was excluded $(P>0.10)$ from this model.

\section{Discussion}

Depression was very common among caregivers of COPD patients at the time of hospitalization for acute exacerbation, but the findings of the current study indicate that depressive symptoms often remit after discharge. However, our results also showed that some caregivers who originally reported being depression-free had depression 3 months after the patients they care for were discharged from the hospital. The percentage of caregivers with depressive symptoms after 3 months at home was consistent with previous studies of caregivers of patients with stable $\mathrm{COPD}^{5,6}$ and other chronic conditions..$^{20}$

Spousal caregiving, dyspnea, and severity of airflow limitation were independent factors associated with caregiver depression at the time of hospitalization. The higher odds of depression for spouses/partners may indicate that acute exacerbations are very stressful for them. ${ }^{7}$ In a previous meta-analysis of caregivers of patients with chronic diseases, researchers found that spouses have higher levels of depression and stress than other caregivers and noncaregivers. ${ }^{21}$ The relevance of both dyspnea and severe/very severe COPD is also consistent with previous studies of caregivers of patients with COPD. ${ }^{5,6}$ These results were expected because, as the disease progresses, the burden and responsibilities also tend to increase (eg, monitoring breathlessness, medications, and oxygen therapy). ${ }^{22}$ Illness factors associated with depressive symptoms at the time of hospitalization for acute exacerbation of COPD (severity and dyspnea) were not strong predictors of remission or new episodes of depression after hospital discharge. A possible reason for this finding could 
Table 2 Predictors of caregiver depression during hospitalization of their patients

\begin{tabular}{|c|c|c|c|c|c|}
\hline Variables & Model I & Model 2 & Model 3 & Model 4 & Final model \\
\hline \multicolumn{6}{|l|}{ Context of care } \\
\hline Age & $0.99(0.95-1.03)$ & & & & \\
\hline Female & $3.19(0.49-20.59)$ & & & & \\
\hline Spouse/partner & $5.07(0.85-30.2)^{* *}$ & & & & $2.65(0.85-8.26)^{* *}$ \\
\hline Cohabitation & $0.27(0.04-1.92)$ & & & & \\
\hline \multicolumn{6}{|l|}{ Caregiving demands } \\
\hline Caregiving period $>$ I year & & $3.25(0.54-9.59)$ & & & \\
\hline$>20$ hours per week & & $0.86(0.30-2.44)$ & & & \\
\hline \multicolumn{6}{|l|}{ Caregiver's burden } \\
\hline Low & & Reference & & & \\
\hline Moderate & & $3.73(0.88-5.77)^{* *}$ & & & \\
\hline High & & $3.78(I . I-3.4)^{*}$ & & & Excluded \\
\hline \multicolumn{6}{|l|}{ Caregiver's resources } \\
\hline Normal affective support & & & $0.36(0.09-1.38)$ & & \\
\hline Normal confidential & & & $0.52(0.12-2.21)$ & & \\
\hline Receive help from another caregiver & & & $1.16(0.40-3.39)$ & & \\
\hline \multicolumn{6}{|l|}{ Patient characteristics } \\
\hline Severe/very severe airflow limitation & & & & $4.66(1.67-12.97)^{*}$ & $3.88(1.42-10.65)^{*}$ \\
\hline \multicolumn{6}{|l|}{ Dyspnea score } \\
\hline $0-1$ & & & & Reference & Reference \\
\hline 2 & & & & $1.73(0.35-8.66)$ & $1.89(0.37-9.63)$ \\
\hline$\geq 3$ & & & & $3.53(0.91-13.60)^{* *}$ & $4.10(1.11-15.22)^{*}$ \\
\hline \multicolumn{6}{|l|}{ Frailty of patient } \\
\hline Not frail & & & & Reference & \\
\hline Vulnerable & & & & $0.70(0.17-2.87)$ & \\
\hline Frail & & & & $0.92(0.27-3.17)$ & \\
\hline$\geq 3$ dependencies & & & & $0.74(0.2 \mathrm{I}-2.68)$ & \\
\hline$R^{2}$ & $11.10 \%$ & $12.90 \%$ & $9.9 \%$ & $20.90 \%$ & $24.10 \%$ \\
\hline
\end{tabular}

Notes: Data represent odds ratio (95\% confidence intervals) unless otherwise noted. $* P<0.05 ; * * P<0.10$.

be the severity of disease being more stressful for caregivers during acute exacerbation than at home.

Our findings on patients' dependence as a determinant of fluctuations in the depressive status of caregivers after hospital discharge are particularly important in light of

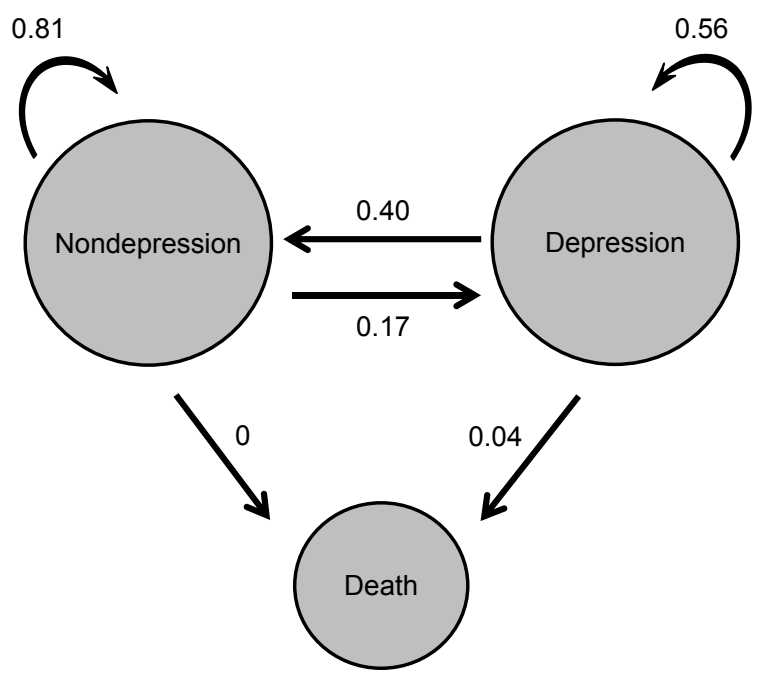

Figure I Probabilities of change between the states of depression, nondepression, and death. the known relevance of hospitalization on the progression of disability. ${ }^{23,24}$

\section{Limitations of this study}

Our findings should be interpreted in light of our study's methodological limitations. We compared caregivers' depression status in two environments: hospital and home. Nevertheless, data were initially collected at the time of hospitalization and it was not possible to know the magnitude of the impact of the hospitalization on the caregivers' depression. Longitudinal studies that assess depression and premorbid health status before hospitalization would be desirable. Depression status after hospital discharge was measured

Table 3 Predictors of remission and new episodes of depression after hospital discharge

\begin{tabular}{lll}
\hline Variables & Remission model & New episodes model \\
\hline$>20$ hours per week & $0.1(0.02-0.65)^{*}$ & - \\
$\geq 3$ dependencies & $0.18(0.03-1.20)^{* *}$ & $9.68(1.74-53.85)^{*}$ \\
at home & & \\
$R^{2}, \%$ & 32.1 & 25.1
\end{tabular}

Notes: Data represent odds ratio ( $95 \%$ confidence intervals) unless otherwise noted. $* P<0.05 ; * * p<0.10$. 
only once at 3 months, and it is likely that there were additional fluctuations between these time points. Moreover, it is possible that the recovery time may be longer; consequently, our results likely underestimate the recovery rates. Third, patients with survival expected to be $<4$ months may determine more depression in caregivers and their exclusion may bias the results. Our decision to exclude them was based on the fact that a 3-month follow-up was planned. Finally, because of the small number of men in the cohort, the results should be generalized to men with caution.

\section{Implications for practice and research}

To the best of our knowledge, this is the first study to provide evidence that the frequency of depression at home is substantially lower than at the time of hospitalization for exacerbation. This was an expected result because studies of other conditions have indicated that hospital admission is stressful for caregivers. ${ }^{21}$ Although dependence to perform several ADLs was not associated with depression at hospitalization, it was the more relevant factor for fluctuations in depressive symptoms after hospital discharge. In our opinion, these two findings are not contradictory. Dependence is not a supplementary workload or source of distress for caregivers during hospitalization because their responsibilities are surrogated by staff assistance. In contrast, the patient being dependent after hospitalization is a more distressing situation for caregivers due to increasing care demands or sadness associated with the loss of independence by a family member. Identifying patients with severe dependence who could be targeted for rehabilitation programs prior to or after hospitalization could reduce the very high rates of depression in caregivers seen after hospitalization.

\section{Conclusion}

This study advances current knowledge on the presence of depressive symptoms among caregivers at the time of hospitalization for exacerbation of COPD and their related change 3 months after the patients they care for return home. Although depression is more common at hospitalization for caregivers who are the spouses of patients with severe illness, the perception of depressive symptoms is dynamic, and many caregivers will not experience depressive symptoms in the middle term. Caregivers are more likely to recover from depression when their patients have few dependencies after hospital discharge. Dependence after discharge is also a strong determinant of new episodes of depression among caregivers. Further research should address caregivers' needs, especially regarding the effectiveness of supportive interventions for dependence and prevention of distress at the time of hospitalization.

\section{Acknowledgments}

The authors wish to thank the patients and personnel of the hospital unit for their cooperation during the course of this study. The study was supported by medical manager of AstraZeneca Pharmaceutical Spain, S.A. and Maite Pérez Hernández.

\section{Disclosure}

The authors report no conflicts of interest in this work.

\section{References}

1. Ko FW, Chan KP, Hui DS, et al. Acute exacerbation of COPD. Respirology. 2016;21(7):1152-1165.

2. Zwerink M, Brusse-Keizer M, van der Valk PD, et al. Self-management for patients with chronic obstructive pulmonary disease. Cochrane Database Syst Rev. 2014;3:CD002990.

3. Caress AL, Luker KA, Chalmers KI, Salmon MP. A review of the information and support needs of family carers of patients with chronic obstructive pulmonary disease. J Clin Nurs. 2009;18(4):479-491.

4. Miravitlles M, Peña-Longobardo LM, Oliva-Moreno J, HidalgoVega A. Caregivers' burden in patients with COPD. Int J Chron Obstruct Pulmon Dis. 2015;10:347-356.

5. Figueiredo D, Gabriel R, Jácome C, Cruz J, Marques A. Caring for relatives with chronic obstructive pulmonary disease: how does the disease severity impact on family carers? Aging Ment Health. 2014; 18(3):385-393.

6. Jácome C, Figueiredo D, Gabriel R, Cruz J, Marques A. Predicting anxiety and depression among family carers of people with chronic obstructive pulmonary disease. Int Psychogeriatr. 2014;26(7):1191-1199.

7. Grant M, Cavanagh A, Yorke J. The impact of caring for those with chronic obstructive pulmonary disease (COPD) on carers' psychological well-being: a narrative review. Int J Nurs Stud. 2012;49(11): 1459-1471.

8. Nakken N, Janssen DJ, van den Bogaart EH, et al. Informal caregivers of patients with COPD: home sweet home? Eur Respir Rev. 2015; 24(137):498-504.

9. Goldberg D, Bridges K, Duncan-Jones P, Grayson D. Detecting anxiety and depression in general medical settings. BMJ. 1988;297(6653): 897-899.

10. Montón C, Pérez-Echevarría MJ, Campos R, García Campayo J, Lobo A. Anxiety scales and Goldberg's depression: an efficient interview guide for the detection of psychologic distress. Aten Primaria. 1993;12(6):345-349.

11. Pearlin LI, Mullan JT, Semple SJ, Skaff MM. Caregiving and the stress process: an overview of concepts and their measures. Gerontologist. 1990;30(5):583-594.

12. Zarit SH, Todd PA, Zarit JM. Subjective burden of husbands and wives as caregivers: a longitudinal study. Gerontologist. 1986;26(3):260-266.

13. Garlo K, O'Leary JR, Van Ness PH, Fried TR. Burden in caregivers of older adults with advanced illness. J Am Geriatr Soc. 2010; 58(12):2315-2322.

14. Broadhead WE, Gehlbach SH, de Gruy FV, Kaplan BH. The DukeUNK Functional Social Support Questionnaire. Measurement of social support in family medicine patients. Med Care. 1988;26(7):709-723.

15. Bellón Saameño JA, Delgado Sánchez A, Luna del Castillo JD, Lardelli Claret P. Validity and reliability of the Duke-UNC-11 questionnaire of functional social support. Aten Primaria. 1996;18(4): 153-163.

16. Hilmer SN, Perera V, Mitchell S, et al. The assessment of frailty in older people in acute care. Australas J Ageing. 2009;28(4):182-188. 
17. Boyd CM, Ricks M, Fried LP, et al. Functional decline and recovery of activities of daily living in hospitalizated, disabled older women: the Women's Health and Aging Study I. J Am Geriatr Soc. 2009;57(10):1757-1766.

18. Hosmer DW, Lemeshow S. Applied Logistic Regression. 2nd ed. Hoboken, NJ: John Wiley \& Sons; 2000.

19. Tabachnick BG, Fidell LS. Using Multivariate Statistics. 6th ed. Boston, MA: Pearson Education; 2013

20. Grov EK, Dahl AA, Moum T, Fosså SD. Anxiety, depression, and quality of life in caregivers of patients with cancer in late palliative phase. Ann Oncol. 2005;16(7):1185-1191.

21. Pinquart M, Sorensen S. Differences between caregivers and noncaregivers in psychological health and physical health: a meta-analysis. Psychol Aging. 2003;18(2):250-267.
22. Simpson AC, Young J, Donahue M, Rocker G. A day at a time: caregiving on the edge in advanced COPD. Int J Chron Obstruct Pulmon Dis. 2010; 5(1):141-151.

23. Connors AF Jr, Dawson NV, Thomas C, et al. Outcomes following acute exacerbation of severe chronic obstructive lung disease. Am J Respir Crit Care Med. 1996;154(4 Pt 1):959-967.

24. Lenz EH, Perkins S. Coronary artery bypass graft surgery patients and their family member caregivers: outcomes of a family-focused staged psychoeducational intervention. Appl Nurs Res. 2000;13(3):142-150.

International Journal of COPD

\section{Publish your work in this journal}

The International Journal of COPD is an international, peer-reviewed journal of therapeutics and pharmacology focusing on concise rapid reporting of clinical studies and reviews in COPD. Special focus is given to the pathophysiological processes underlying the disease, intervention programs, patient focused education, and self management protocols.

\section{Dovepress}

This journal is indexed on PubMed Central, MedLine and CAS. The manuscript management system is completely online and includes a very quick and fair peer-review system, which is all easy to use. Visit http://www.dovepress.com/testimonials.php to read real quotes from published authors.

Submit your manuscript here: http://www.dovepress.com/international-journal-of-chronic-obstructive-pulmonary-disease-journal 